\title{
Forecasting "friends forever": A longitudinal investigation of sustained closeness between best friends
}

\author{
ANDREW M. LEDBETTER, ${ }^{a}$ EM GRIFFIN, ${ }^{b}$ AND GLENN G. SPARKS ${ }^{c}$ \\ ${ }^{a}$ Ohio University; ${ }^{b}$ Wheaton College; ${ }^{c}$ Purdue University
}

\begin{abstract}
Using data collected across 19 years, the chief goal of this study was to discover predictors of continued relational closeness between best friends. Participants were same-sex and cross-sex best friend pairs recruited from a small Midwestern college. In 1983, participants completed several tests and activities designed to assess facets of intimacy, with follow-up studies in 1987 and 2002 measuring relational closeness. Regression analysis indicates that both manifest similarity and months of closeness in 1983 are associated with relational closeness in 2002 . These results suggest that the investment of resources in the friendship and similarity between friends facilitate friendship longevity and that Kelley et al.'s (1983) conceptualization of closeness as related to interdependence is empirically robust.
\end{abstract}

Though close relationship research has demonstrated friendship's importance, it has also shown friendship's potential fragility throughout the adult years, with changing work and family responsibilities serving as barriers to maintaining existing friendships (Duck, 1994; Rawlins, 1992). The practical challenges of maintaining long-term friendships highlight the importance of understanding the factors that might facilitate this type of relationship. The chief goal of this longitudinal

Andrew M. Ledbetter, Department of Communication Studies, University of Kansas; Em Griffin, Communication Department, Wheaton College; Glenn G. Sparks, Department of Communication, Purdue University.

Andrew M. Ledbetter is now at Ohio University.

An earlier version of this manuscript was presented at the annual meeting of the National Communication Association, Chicago (November, 2004). A report on the second phase of this longitudinal study was published in Journal of Social and Personal Relationships (Griffin \& Sparks, 1990). A separate manuscript from this data set has been accepted for publication in a forthcoming issue of New Media \& Society.

Correspondence should be addressed to Andrew M. Ledbetter, Ohio University, School of Communication Studies, Lasher Hall, Athens, OH 45701, e-mail: Andrew.Ledbetter.1@ohio.edu. study is to extend previously reported results (Griffin \& Sparks, 1990) by discovering interactive variables that forecast closeness in the relationships of college best friends across 19 years.

Johnson, Wittenberg, Villagran, Mazur, and Villagran (2003) argue that closeness is an important criterion variable for measuring the status of a friendship. Thus, closeness is the chief construct of interest in this study, treated here as an indicator of overall friendship quality. Our operationalization of closeness follows Kelley et al.'s (1983) definition of a close relationship as "one of strong, frequent, and diverse interdependence that lasts over a considerable period of time" (p. 38; italics in original). Thus, we conceptualize closeness as closely linked to dyadic interdependence manifested by a variety of cognitions and behaviors.

Although closeness is an important marker of friendship status, developmental changes over the life course may create systemic pressures that threaten continued closeness. For example, whereas Rawlins (1992) argues that college is a fertile period for friendship 
formation, he also notes that adult friendships often compete with romantic relationships and career responsibilities for time, energy, and other resources. In a related line of research, Johnson et al. (2003) report empirical evidence suggesting that the experience of closeness may vary throughout the course of a friendship, noting that future studies are needed to determine why different friendships exhibit markedly different experiences of closeness. The goal of this study is to help answer this call, making a first attempt at identifying some factors that contribute to friendship closeness across decades.

In the first published report of this research project that examined friendship data collected 4 years after the initial phase (1987), none of the 1983 variables (see Griffin \& Sparks, 1990 , for details) were associated with friendship closeness in 1987. Because previous research suggests that life course changes can influence enduring friendship closeness (e.g., Rawlins, 1992), it seems possible that some variables may predict friendship in the 2002 phase of this study that did not do so in 1987. Despite the inconclusive results obtained in 1987, we advance the following research question: Which, if any, friendship factors predict closeness 19 years after the first study?

\section{Method}

\section{Participants}

Participants were initially recruited in 1983 from a small, private, Protestant liberal arts college near a large city in the United States Midwest. All participants were between 18 and 25 years old during this initial phase and were predominantly Caucasian. After volunteering to participate, a member of the research team asked both members of the dyad privately and individually how many others on campus they considered a closer friend than his or her partner in the research project. If either member of a friendship dyad stated that he or she was closer to even one other person on campus, we discarded the data from that dyad from analysis. The resultant sample consisted of three different types of friendship based on the sex composition of the dyad: male-male dyads $(n=15)$, female-female dyads $(n=$ 17), and cross-sex, or male-female platonic dyads $(n=13)$. In both Phases 2 and 3, participants returned surveys via postal mail. In 1987,84 of the 90 participants $(93 \%)$ in the original study participated in Phase 2. At least one partner responded from all 44 friendship pairs, with one male-male pair removed from the study due to the death of one of the friendship partners. In 2002, 58 of the 90 participants $(64 \%)$ in the original study participated in Phase 3. At least one partner from 38 of the 44 dyads responded $(86 \%)$. The final 2002 sample contained 11 male-male, 16 femalefemale, and 11 cross-sex pairs. Participant loss is one of the greatest challenges in panel-based longitudinal research (Babbie, 2001). Fortunately, the alumni office generously provided assistance in tracking participants, thus resulting in the remarkably high retention rates reported here. Although a convenience sample has its limitations, it is justified in this situation due to the scarcity of longitudinal studies of friendship.

We examined demographic changes across the second and third phases of the study. To facilitate comparison between Phases 2 and 3, demographic statistics were examined only for those participants who responded in the 2002 phase of the study. In 1987, $29(50 \%)$ of the individual participants were single, 24 (41.4\%) were married, and $2(3.4 \%)$ were engaged (the remaining percentage did not report their marital status). By 2002, only 7 (12.1\%) were single and unmarried, whereas $43(74.1 \%)$ were married and $4(6.9 \%)$ were divorced. Regarding children, $42(72.4 \%)$ of the participants were childless in 1987 (average number of children $=0.2)$, whereas only $11(19.0 \%)$ of the participants had no children in 2002 (mean number of children $=2.3$ ). Participants reported a mean of 5.8 changes of residence since leaving college. Not surprisingly, then, computation of the distance between friends in 2002 revealed very few friendship dyads who lived within 50 miles of each other $(n=5)$, with an average distance across the sample of approximately 895 miles. Overall, these demographic results suggest the increasing importance of family life and geographical separation that Rawlins (1992) describes. 


\section{3 measures of friendship characteristics}

These measures are described here only briefly. A fuller description of the measures can be found in Griffin and Sparks (1990).

Months of closeness. Participants reported when they first became close friends. Months of closeness ranged from 3 to 84 months $(M=$ 20.6, $S D=16.2$ ).

Self-disclosure. Each friend completed an inventory of open-ended questions based on Jourard's (1971) six-topic typology of disclosure types. The total number of matches between friends were summed for the pair.

Touch. Friends rated the touching behavior within their relationship on a Guttman scaleogram (Babbie, 2001) of 21 touch behaviors ranking from low intimacy (hand shake) to high intimacy (sexual intercourse). A higher score on this measure indicated more intimate touching behavior.

Perceived status difference. Friends rated their status relative to each other in six different domains (e.g., physical attractiveness, financial resources). A total score of status difference was obtained by summing over the values of the six status scores.

Protection of partner. Participants rated the degree to which they avoided discussion of a list of 33 topics because they would cause their friend pain (Rawlins, 1983). The partner protection score was obtained by tallying the number of topic areas avoided in conversation.

Similarity of major. Subjects reported their major area of study. Partners were marked as similar on this dichotomous variable if they fell into the same general category of study.

Password game efficiency. Each pair played the word game Password with each other. Both partners in the dyad were given a set of seven words. For each word, the partner provided her or his friend with one-word clues intended to elicit the target word from the friend. A point was scored for each clue used in guessing a word. The lower the score, the more effectively the pair communicated with each other.

To reduce the number of independent variables and identify specific subsets of friendship qualities that might be represented in the data, we submitted these seven variables to a principal components factor analysis with varimax (orthogonal) rotation (using the criterion of eigenvalue $\lambda>1.00$ ). Using a $.60 / .40$ criterion to obtain factor structure (McCroskey \& Young, 1979), months of friendship crossloaded on two factors. Removing this variable from the factor analysis produced a three-factor solution that met the $.60 / .40$ criterion, accounting for $68.50 \%$ of the total variance. To test the stability of this factor solution and examine interfactor correlations, we also submitted these variables to principal components factor analysis with promax (nonorthogonal) rotation. The structure of this solution did not differ from the varimax rotation and revealed no strong or significant interfactor correlations (see Table 1).

First, friendships differed in the amount of Expressed Intimacy in the friendship, performed verbally through self-disclosure and nonverbally through touching behavior. The second factor reflects the level of Perceived Difference in the friendship, as represented by perceived status difference and protection of the partner through topic avoidance. The final factor represents Manifest Similarity. In contrast to the perceptions of partner difference measured in the second factor, friends who scored high on this factor objectively demonstrated their similarity through participating in similar academic programs and efficiently engaging in word association in the Password game. For each dyad, these three factor scores were computed and saved using the regression method on the promax rotation factor solution (Johnson \& Wichern, 2002).

Traditional indices of reliability, such as Cronbach's alpha $(\alpha)$, capitalize on the number of items in the measure to produce reliability estimates (Kopalle \& Lehmann, 1997). A more appropriate indication of reliability for two-item measures is the simple Pearson correlations between the items. These correlation coefficients indicate at least a reasonable 
Table 1. Factor analysis and correlations for 1983 friendship measures

\begin{tabular}{lccc}
\hline \hline & $\begin{array}{c}\text { Factor } 1 \\
\text { (Expressed } \\
\text { Intimacy) }\end{array}$ & $\begin{array}{c}\text { Factor } 2 \\
\text { (Perceived } \\
\text { Difference) }\end{array}$ & $\begin{array}{c}\text { Factor 3 } \\
\text { (Manifest } \\
\text { Similarity) }\end{array}$ \\
\hline Self-disclosure & $.75(.75)$ & $.22(.27)$ & $-.10(-.04)$ \\
Touch & $.86(.86)$ & $-.05(.01)$ & $.13(.19)$ \\
Partner protection & $-.04(.01)$ & $.86(.85)$ & $-.15(-.12)$ \\
Total status difference & $.27(.34)$ & $.75(.77)$ & $.28(.32)$ \\
Password score & $-.18(-.22)$ & $.15(.12)$ & $-.76(-.77)$ \\
Similarity of academic major & $-.15(-.08)$ & $.19(.20)$ & $.75(.74)$ \\
Eigenvalue & 1.72 & 1.24 & 1.16 \\
Percentage variance & 28.63 & 20.62 & 19.25 \\
accounted for & & & \\
Interfactor correlations & & & \\
$\quad$ 1. Expressed Intimacy & 1.00 & 1.00 & .00 \\
$\quad$ 2. Perceived Difference & .14 & .06 & .14 \\
$\quad$ 3. Manifest Similarity & .15 & & $.48^{* *}$ \\
Association with & & -.03 & \\
relational closeness & & -.15 & \\
$\quad$ 1987 closeness & & & \\
2002 closeness & -.16 & & \\
\hline \hline
\end{tabular}

Note. Loadings outside parentheses report the varimax (orthogonal) rotation solution, whereas loadings inside parentheses report the pattern matrix of the promax (nonorthogonal) rotation solution. Italicized loadings indicate primary loadings above .60. All interfactor correlations are not statistically significant at $\alpha=.05$.

$* * p<.01$.

percentage of shared variance between the two items for Expressed Intimacy $(r=.36)$, Perceived Difference $(r=.40)$, and Manifest Similarity $(r=-.20)$. The size of these correlation coefficients (Keyton, 2006) suggests sufficient factor reliability for proceeding with this exploratory investigation.

\section{Phases 2 (1987) and 3 (2002)}

Demographic information. In both the second and third phases, participants reported their marital status and number of children. In the third phase, they also reported how many times they had moved since leaving campus.

Closeness. $\quad$ Based on Kelley et al.'s (1983) definition of closeness as characterized by "strength, frequency, diversity, and duration" (p. 38), we developed measures that assess each of these four properties. First, each participant indicated the relative strength of the friendship by reporting how many friends were regarded as closer than the study partner. Second, participants reported frequency of contact by recording the number of face-toface, mail, phone, and e-mail (in 2002 phase only) contacts they had with their partners during the past 12 months. Third, participants reported how often they and their friends kept rules of friendship (e.g., "striving to make him/her happy when together"; Argyle \& Henderson, 1984). We conceptualized rule keeping as one potential indicator of the level of diversity within the friendship, as it stands to reason that friends who keep more rules are more interdependent in many areas of life. Fourth, participants indicated commitment to the friendship by estimating the probability that the relationship would continue several years into the future. Finally, participants reported caring behavior within the friendship by completing Maxwell's (1985) Close Relationship Questionnaire (CRQ). Whereas Kelley 
et al. (1983) do not view caring behavior as necessarily indicating closeness, they acknowledge that such behavior may characterize some kinds of close relationships. The CRQ is composed of 15 items measured on a seven-point semantic differential scale. The scale demonstrated excellent reliability $(\alpha=.96)$ in the 2002 phase of this study. As a whole, these five closeness measures were high in internal consistency in both $1987(\alpha=.92)$ and $2002(\alpha=$ $.94)$, and so we combined them into a single measure of friendship closeness.

In 1987, for those pairs from which only one survey was received, we used individual closeness scores as a proxy for scores for the dyad. Strong correlations emerged between the individual scores of dyads where both members returned a survey, ranging from .60 to .88 and averaging .76 . These strong correlations supported using individual scores when information from both members of the dyad was unavailable. In 2002, individual scores were also used as a proxy for dyad scores, as high correlations between the individual scores of dyads who returned both surveys justified the use of this technique $\left(r_{\text {contact }}=.80\right.$, $r_{\text {behavior }}=.87, r_{\text {strength }}=.69, r_{\text {commitment }}=.97$, $r_{\text {crq }}=.85$ ). Additionally, a series of independent samples $t$ tests probed whether dyads who did not respond in 2002 differed significantly on the seven 1983 predictor measures and 1987 closeness. Other than a significant difference in means for partner protection, $t(42)=$ $-2.73, p<.01$, no significant differences in means or standard deviations emerged, thus suggesting that subject loss was random rather than systematic.

\section{Results}

Before examining the research question, descriptive statistics of the five variables composing the closeness measure were analyzed using a repeated measures analysis of variance with study phase as a within-subjects factor and the five dependent variables at both time points as criterion variables. The omnibus test for study phase revealed a significant difference in means between 1987 and 2002, Wilks' $\lambda=.36, F(5,33)=11.75, p<.01$, partial $\eta^{2}=.64$. Subsequent one-way tests indicated significantly decreased closeness for four of the five measures, with only the CRQ score approaching but not achieving statistical significance $(p>.05$; contact lead author for univariate results).

The research question asked whether any 1983 friendship measures would predict relational closeness in 2002. We first investigated this research question by examining the Pearson product-moment correlations between the seven 1983 predictor variables and 2002 closeness. Inspection of the correlation matrix indicated significant correlations between 2002 closeness and 1983 months of closeness $(r=$ $.52, p<.01)$, similar academic major $(r=.37$, $p<.05)$, and Password score $(r=-.36$, $p<.05)$.

Next, two separate regression models examined the relationship between the seven predictor variables and 2002 closeness. Because the product-moment correlation between 1987 and 2002 closeness revealed a strong and significant relationship $(r=.51, p<.01)$, the first step in each regression controlled for 1987 closeness. In the first regression (see Table 2), the second step entered the three factor scores and months of closeness, producing a significant change in variance explained (27.1\%) and increasing the total variance accounted to $50.69 \%$. Examination of the beta weights revealed that months of closeness was a significant predictor of 2002 closeness, though Manifest Similarity approached statistical significance $(p>.05)$. The third step removed 1987 closeness to examine the predictive power of the variables without regard to previously measured closeness. Both months of closeness and Manifest Similarity were significant predictors in this third step.

Because some factors exhibited marginal reliability, we probed the results of the first regression analysis with a second regression model using the seven original 1983 variables (see Table 2). After controlling for 1987 closeness in the first step, we entered all seven predictors in the second step using the stepwise entry method. Months of closeness was the only significant predictor of 2002 closeness in this model, though Password score approached statistical significance $(p>.05)$. To explore this potential predictor, we forced 
Table 2. Summary of regression analysis for factors predicting 1987 and 2002 friendship closeness $(N=37)$

\begin{tabular}{|c|c|c|c|c|c|c|}
\hline Variables entered & $B$ & $S E$ & $\beta$ & $t$ & $F$ & $\Delta R^{2}$ \\
\hline \multicolumn{7}{|l|}{ Model for factor scores } \\
\hline Step 1 & & & & & $10.77 * * *$ & $.24 * * *$ \\
\hline 1. 1987 closeness & .50 & .15 & .49 & $3.28 * * *$ & & \\
\hline Step 2 & & & & & $6.35 * * *$ & $.27 * * *$ \\
\hline 1. 1987 closeness & .39 & .15 & .38 & $2.69 * *$ & & \\
\hline 2. Expressed Intimacy & .05 & .15 & .05 & .34 & & \\
\hline 3. Perceived Difference & -.09 & .13 & -.09 & .67 & & \\
\hline 4. Manifest Similarity & .28 & .14 & .27 & $1.96^{*}$ & & \\
\hline 5. Months of closeness in 1983 & .02 & .01 & .37 & $2.73 *$ & & \\
\hline Step 3 (1987 closeness removed) & & & & & $5.14 * * *$ & $-.12 * *$ \\
\hline 1. Expressed Intimacy & -.10 & .15 & -.10 & -.69 & & \\
\hline 2. Perceived Difference & -.09 & .14 & -.10 & -.66 & & \\
\hline 3. Manifest Similarity & .39 & .15 & .38 & $2.59 * *$ & & \\
\hline 4. Months of closeness in 1983 & .02 & .01 & .37 & $2.49 * *$ & & \\
\hline \multicolumn{7}{|l|}{ Model for raw variables } \\
\hline Step 1 & & & & & $10.77 * * *$ & $.24 * * *$ \\
\hline 1. 1987 closeness & .50 & .15 & .49 & $3.28 * * *$ & & \\
\hline Step 2 & & & & & $12.93 * * *$ & $.20 * * *$ \\
\hline 1. 1987 closeness & .44 & .14 & .42 & $3.25 * * *$ & & \\
\hline 2. Months of closeness in 1983 & .03 & .01 & .45 & $3.43 * * *$ & & \\
\hline \multicolumn{7}{|l|}{ Step 3} \\
\hline 1. 1987 closeness & .43 & .13 & .42 & $3.31 * * *$ & & \\
\hline 2. Months of closeness in 1983 & .02 & .01 & .39 & $3.06 * * *$ & & \\
\hline 3. Password score & -.02 & .01 & -.24 & $-1.911 *$ & & \\
\hline \multicolumn{7}{|l|}{ Step 4} \\
\hline 1. 1987 closeness & .48 & .14 & .47 & $3.35 * * *$ & & \\
\hline 2. Password score & -.03 & .01 & -.33 & $-2.37 * *$ & & \\
\hline
\end{tabular}

${ }^{*} p<.07 .{ }^{* *} p<.05 .{ }^{* * *} p<.01$.

the entry of Password score into the regression model in the third step and removed 1983 months of closeness in the fourth step. Password score was a predictor in this final step of the model. Viewed as a whole, the results of the correlational and regression analyses suggest that months of closeness in 1983 is the strongest predictor of 2002 closeness, with Manifest Similarity (particularly as indicated by Password score) as an important yet somewhat less potent predictor.

\section{Discussion}

The purpose of the third phase of this study was to search for potential predictors of long-term friendship after friends passed through years likely containing important life course changes (Rawlins, 1992). Months of closeness in 1983 and Manifest Similarity (particularly as represented by ability to access similar cognitions in the Password game) best predicted closeness 19 years later. Three conclusions from these findings are worth highlighting.

First, despite the central focus of verbal and nonverbal openness in some theories of close relationships (e.g., Taylor \& Altman, 1987), expression of intimacy in 1983 did not predict future relational closeness between friends in this sample. Whereas behaviors that express intimacy may help develop an initial level of 
closeness (Jourard, 1971), perhaps their importance wanes as a friendship progresses. Perceived Difference also did not predict relational closeness in 2002. Although previous work has shown that perception of difference is inversely related to initial interpersonal attraction (Berscheid \& Reis, 1998), friends in this study already considered each other best friends in 1983, suggesting that perceived differences are less important once a high degree of closeness has been reached.

Second, months of friendship and Manifest Similarity did predict relational closeness 19 years after the initial study. Months of friendship may represent the degree to which friends have invested time and effort in the friendship. The investment model, which is closely linked to interdependence theory (Rusbult, 1980), predicts that investing irretrievable resources in a relationship is associated with increased commitment to maintaining that relationship. Over time, the investment of irretrievable resources in a friendship may function as a powerful incentive to maintain the relationship so that those resources are not lost, thereby generating interdependent closeness in the dyad. Likewise, Password score may indicate investment in understanding how each other thinks and communicates, or a fundamental level of similarity that fostered close friendship development (see Berscheid \& Reis, 1998). From an interdependence perspective, it stands to reason that friends who are similar to one another may be able to build interdependent closeness more easily (see Hollingshead \& Brandon, 2003).

Third, it is worth noting that this association between interdependence and ongoing closeness occurred in spite of the significant changes in marital status, number of children, and geographic distance between friends. This suggests that a strong level of interdependence can surpass even the challenges to ongoing friendship presented by life transitions common in early and middle adulthood (Rawlins, 1992). Nevertheless, we did not explicitly test the degree to which changes between demographic homogeneity and heterogeneity are associated with closeness, as Rawlins suggests. Such an association awaits further empirical investigation.
Taken as a whole, these results suggest that interdependence theory is a useful framework for conceptualizing processes that facilitate enduring friendship closeness. In other words, friends whose cognitions and behaviors are closely linked seem more likely to remain close. Either time invested in the friendship or inherent similarity may build such interdependence, which in turn leads to friendships that stand the test of time. Perhaps these associations did not emerge in 1987 because the meaning attached to sustained closeness changes with the length of the friendship (see Hartup \& Stevens, 1997, for discussion of such changes in the nature of friendship throughout the life course). In other words, ongoing closeness across decades often may necessitate a level of interdependence unnecessary for friendships that endure only a few years. Alternatively, yet relatedly, it seems plausible that the predictive association between interdependence and future closeness might increase with the passage of time in enduring friendships. Thus, the small sample size may have prevented detection of such an association in 1987, yet provided sufficient power to produce a significant effect in 2002 . Further research is needed to determine whether interdependence processes function similarly across both short- and long-time intervals within ongoing relationships.

While recognizing the value of relational data collected over a period of 19 years, it is still important to keep in mind that these results are not generalizable to other populations. It seems plausible that certain dimensions of cultural difference, such as individualism versus collectivism, might influence the importance, salience, and maintenance behaviors attached to ongoing friendship across cultures. Even those who hold cultural values similar to our population and yet did not attend college may attach different meanings to friendships built during early adulthood. It is also worth noting that these data originate from a Protestant religious culture, and that shared religious beliefs regarding friendship may generate different results than a similar study conducted with a population containing different or more heterogeneous religious beliefs. Though the sample size is small, the retention rate ( $86 \%$ of the dyads) across the 
19 years of the research is remarkably high. Although there is always some concern about the reliability of two-item measures, low reliability should lead to Type II, rather than to Type I, error (Kline, 2005). The fact that Manifest Similarity did significantly predict 2002 closeness mitigates against the general concern that low reliability may have accounted for any null results. Despite these weaknesses, this study has several strengths. Its chief strength is that it is a first step in conducting longitudinal research on close friendships over decades, an avenue of research which is needed, yet rarely done (Duck, 1994; Hartup \& Stevens, 1997).

Our results suggest at least two practical applications for those who wish to maintain ongoing friendship closeness. First, friendship strength seems related to friends' ability to communicate efficiently (as represented by the Password score in this study). Consequently, those friends who wish to remain close may wish to invest time discussing how each other makes sense of the world. Such communication skill and mutual understanding may help friends successfully transition through life changes that threaten friendship stability. Second, our results provide some indirect evidence that lapsed friendships might be restarted successfully if the friends had achieved a strong degree of interdependent closeness.

The results of this study offer hope that friendship processes can be understood across time rather than only in the moment. In particular, interdependence theory seems to be a useful future direction for developing theory that explains enduring friendship closeness. The predictors found here suggest that such longitudinal research is worth doing and that such theory can be developed, leading to a richer understanding of the development and maintenance of friendship.

\section{References}

Argyle, M., \& Henderson, M. (1984). The rules of friendship. Journal of Social and Personal Relationships, 1, 211-237.
Babbie, E. (2001). The practice of social research (9th ed.). Belmont, CA: Wadsworth.

Berscheid, E., \& Reis, H. T. (1998). Attraction and close relationships. In D. T. Gilbert, S. T. Fiske, \& L. Gardner (Eds.), Communication of social support: Messages, interactions, relationships, and community (pp. 175-195). Thousand Oaks, CA: Sage.

Duck, S. (1994). Meaningful relationships: Talking, sense, and relating. Thousand Oaks, CA: Sage.

Griffin, E., \& Sparks, G. G. (1990). Friends forever: A longitudinal exploration of intimacy in same-sex friends and platonic pairs. Journal of Social and Personal Relationships, 7, 29-46.

Hartup, W. W., \& Stevens, N. (1997). Friendships and adaptation in the life course. Psychological Bulletin, $121,355-370$.

Hollingshead, A. B., \& Brandon, D. P. (2003). Potential benefits of communication in transactive memory systems. Human Communication Research, 29, 607-615.

Johnson, A. J., Wittenberg, E., Villagran, M. M., Mazur, M., \& Villagran, P. (2003). Relational progression as a dialectic: Examining turning points in communication among friends. Communication Monographs, 70, 230-249.

Johnson, R. A., \& Wichern, D. W. (2002). Applied multivariate statistical analysis (5th ed.). Upper Saddle River, NJ: Prentice Hall.

Jourard, S. (1971). Self-disclosure: An experimental analysis of the transparent self. New York: John Wiley.

Kelley, H., Berscheid, E., Christensen, A., Harvey, J., Huston, T., Levinger, G., et al. (1983). Analyzing close relationships. In H. Kelley et al. (Eds.), Close relationships (pp. 20-67). New York: W.H. Freeman.

Keyton, J. (2006). Communication research: Asking questions, finding answers (2nd ed.). New York: McGraw-Hill.

Kline, R. B. (2005). Principles and practice of structural equation modeling (2nd ed.). New York: Guilford.

Kopalle, P. K., \& Lehmann, D. R. (1997). Alpha inflation?: The impact of eliminating scale items on Cronbach's alpha. Organizational Behavior and Human Decision Processes, 70, 189-197.

Maxwell, G. M. (1985). Behaviour of lovers: Measuring the closeness of relationships. Journal of Social and Personal Relationships, 2, 215-238.

McCroskey, J. C., \& Young, T. J. (1979). The use and abuse of factor analysis in communication research. Human Communication Research, 5, 375-382.

Rawlins, W. K. (1983). Openness as problematic in ongoing friendships: Two conversational dilemmas. Communication Monographs, 50, 1-13.

Rawlins, W. K. (1992). Friendship matters: Communication, dialectics, and the life course. New York: Aldine de Gruyter.

Rusbult, C. E. (1980). Commitment and satisfaction in romantic associations: A test of the investment model. Journal of Experimental Social Psychology, 16, 172-186.

Taylor, D., \& Altman, I. (1987). Communication in interpersonal relationships: Social penetration processes. In M. Roloff \& G. Miller (Eds.), Interpersonal processes: New directions in communication research (pp. 257277). Newbury Park, CA: Sage. 